\title{
ANALISIS KELEMBAGAAN TERHADAP PELAKSANAAN PROGRAM DEVERSIFIKASI PANGAN DI PASURUAN
}

\author{
Teguh Sarwo Aji ${ }^{1)}$, Novi Itsna Hidayati ${ }^{2)}$ \\ 1) Fakultas Pertanian Universitas Yudharta Pasuruan \\ Email : teguh@yudharta.ac.id \\ 2) Fakultas Pertanian Universitas Yudharta Pasuruan \\ Email : noviitsna@yahoo.com
}

\begin{abstract}
ABSTRAK
Until now it HAD a lot of institutions formed to participate in addressing the problem of providing food for the people. Starting from the institution handling food producers, marketing and distribution of food, food-related capital activities, food safety, food industry and other aspects of food. There was an institutional official government institutions, non-governmental pure, or which was the formal and informal collaboration between government and society. This study aims to identify local institutions that can be used to support the acceleration of food diversification program; analyze the role of local institutions based on their potential to support the acceleration of food diversification program in Pasuruan. In areas of research results show that there are 27 (nineteen) of local institutions that have the potential to support the acceleration of food diversification program. The institution consists of 4 institutional family welfare programs, 4 village consultative body, 4 institutional farmer groups, 4 institutional study, 3 institutional youth clubs and 4 farmers cooperative women. Based on the potential role of local institutions in supporting the acceleration of food diversification program in Pasuruan shows that institutional diversification potentially support the Food program was the first classification, namely the family welfare programs of Village Gerbo, village consultative body of Gerbo, village consultative body of Pucang Sari, family welfare programs of Pucang Sari, Farmers Group of Pucang Sari, family welfare programs of Village Suwayuwo, farmers group of Gerbo , Men Jam'iah Tahlil of Pucang Sari, Farmers Group of Suwahyuwo, family welfare programs of Pandaan Village, farmers cooperative women of Gerbo, farmers cooperative women of Pucang Sari, NU Moslem of Pandaan, NU Moslem of Suwayuwo
\end{abstract}

\section{Keywords: local institutional, food diversification}

\section{PENDAHULUAN}

Sampai saat ini telah banyak kelembagaan yang dibentuk untuk ikut menangani masalah penyediaan pangan untuk masyarakat. Mulai dari kelembagaan yang menangani produsen pangan, pemasaran dan distribusi pangan, permodalan untuk kegiatan terkait pangan, keamanan pangan, industri pangan dan berbagai aspek pangan lainnya. Kelembagaan ini ada yang merupakan kelembagaan resmi pemerintah, murni swadaya masyarakat, atau yang merupakan kolaborasi formal maupun non formal antara pemerintah dan masyarakat.
Peranan kelembagaan pangan tersebut masih belum memenuhi harapan berbagai pihak. Hal ini sering disebabkan karena pengelola kelembagaan tersebut tidak berasal dari populasi individu yang memang secara langsung menggeluti masalah pangan. Kelembagaan-kelembagaan lokal tersebut sangat potensial untuk memberdayakan masyarakat dalam ketahanan pangan contohnya seperti yang disampaikan oleh Nurcahayati (2008) bahwa Kelembagaan Pemberdayaan Kesejahteraan Keluarga (PKK) dengan struktur banyak kelompok kerja (pokja) bisa mewadahi kegiatankegiatan ketahanan pangan. Kegiatan 
penganekaragaman pangan belum tersentuh, dan hanya terbatas pada intensifikasi pekarangan rumah tangga berupa kegiatan penanaman tanaman obat. Pola penganekaragaman pangan dan pemenuhan gizi yang lebih baik, dapat dilakukan di posyandu. Lembaga ini terkait dengan kegiatan kesehatan masyarakat khususnya ibu dan anak. Selain itu PKK (TP PKK) dapat menjalin kemitraan dengan lembagalembaga pemerintah maupun non pemerintah selagi programnya sejalan dan memiliki kesamaan visi dan misi.

Kabupaten Pasuruan adalah daerah yang memiliki banyak pesantren dengan tokohtokoh masyarakat yang mempunyai pengaruh dimasyarakat. Kelembagaan lokal yang banyak ditemui di Pasuruan antara lain adalah kelembagaan keagamaan, misalnya lembaga tahlil. Menurut Rahayu AS (2006), (1) Lembaga Tahlil sebagai institusi lokal tradisional keagamaan yang ada mempunyai kekuatan yang tidak dimiliki oleh institusi formal yang ada, yaitu berupa kedekatannya dengan masyarakat tingkat bawah, dan lebih peka dengan kebutuhan masyarakat, sehingga keberadaannya sangat menentukan sekali akan keberhasilan sebuah pembangunan; (2) Lembaga Tahlil sebagai institusi lokal tradisional keagamaan merupakan sarana yang efektif untuk terjalinnya komunikasi dua arah antara pemerintah dan masyarakat, sehingga misunderstanding antara pemerintah dan masyarakat bisa terhindar; (3) Lembaga Tahlil adalah sarana yang paling efektif untuk menumbuh kembangkan keswadayaan masyarakat dalam pembangunan, sehingga ketergantungan masyarakat akan peran pemerintah dalam pembangunan akan semakin berkurang dan akan mampu menciptakan kemandirian masyarakat; (4) Lembaga Tahlil telah mengalami berbagai perubahan yang mendasar. Perubahan yang dimaksudkan adalah orientasi keberadaannya yang semula bergerak dalam bidang ritual keagamaan, namun selaras dengan tuntutan perkembangan zaman serta semakin kompleknya kebutuhan masyarakat mengakibatkan lembaga ini juga bergerak dalam bidang sosial ekonomi; (6) Institusi/lembaga yang berdasarkan pada adat istiadat setempatlah yang merupakan sarana yang potensial bagi pembangunan desa.

\section{Rumusan Masalah}

Dari uraian tersebut diatas, maka dapat dirumuskan beberapa permasalahan yaitu :

1. Kelembagaan lokal apasaja yang terdapat di lokasi penelitian;

2. Bagaimana peran kelembagaan lokal tersebut berdasarkan potensinya dalam mendukung percepatan program diversifikasi pangan di Pasuruan.

\section{Tujuan Penelitian}

Adapun tujuan dari penelitian ini adalah

1. Mengidentifikasi kelembagaan lokal yang dapat digunakan untuk mendukung percepatan program diversifikasi pangan;

2. Menganalisis peran kelembagaan lokal berdasarkan potensinya dalam mendukung percepatan program diversifikasi pangan di Pasuruan.

\section{METODE PENELITIAN}

\section{Metode Penentuan Lokasi Penelitian}

Penentuan lokasi penelitian ini dilakukan secara sengaja (purposive), yaitu diwilayah Kabupaten Pasuruan dengan pertimbangan bahwa Pasuruan sentra produksi padi dan palawija. Selain itu Pasuruan merupakan daerah religius dimana lembaga lokal seperti pesantren dan organisasi masyarakat banyak ditemukan.

\section{Metode Penentuan Responden}

Responden dalam penelitian ini adalah semua kelembagaan lokal yang terdapat di lokasi penelitian yaitu di Kecamatan Pandaan, Sukorejo, Purwosari, Purwodadi. Dengan demikian penelitian ini adalah penelitian sensus.

\section{Metode Analisis Data}

Metode Analisis Data sesuai dengan tujuan penelitian maka data-data yang telah dikumpulkan baik data kualitatif maupun 
data kuantitatif kemudian dilanjutkan dengan langkah sebagai berikut :

1. Editing : Editing data dilakukan dengan merekam jawaban yang ditulis dalam kuesioner untuk mengetahui ketepatannya.

2. Tabulasi : Tabulasi data dilakukan dengan menyusun data kedalam tabel.

3. Metode analisis yang digunakan dalam penelitian ini, yaitu : (1) analisis diskriptif; dan (2) analisis cluster.

\section{HASIL DAN PEMBAHASAN}

\section{Karakteristik kelembagaan lokal}

a. Karakteristik kelembagaan lokal berdasarkan identitas kelembagaan

Sebagian besar yaitu sebesar 74,03\% kelembagaan lokal yang ada di 4 kecamatana daerah penelitian sudah lama berdiri. Hal ini berarti keberadaan kelembagaan lokal tersebut sudah menjadi bagian dari masyarakat di daerah itu. Selain itu juga diketahui bahwa kelembagaan lokal tersebut mempunyai jumlah anggota rata-rata dibawah 100 orang (cukup banyak). Berdasarkan hal-hal tersebut diatas maka apabila kelembagaan lokal tersebut diikut sertakan dalam program percepatan DPG akan berdampak baik bagi terwujudnya percepatan diversifikasi pangan dan gizi di masyarakat.

b. Karakteristik kelembagaan lokal berdasarkan kapasitas kelembagaan (kondisi internal)

Karakteristik kelembagaan lokal berdasarkan kapasitas kelembagaan (kondisi internal), tersaji pada tabel-tabel berikut ini. Karakteristik yang pertama berdasarkan keterlibatan lembaga dalam program diversifikasi pangan. Sebagian besar kelembagaan lokal yang ada di daerah penelitian mempunyai program kerja walaupun program kerja tersebut tidak tertulis. Tetapi dari program-program kerja yang ada belum dijalankan. Kelembagaan lokal yang tidak menjalankan program kerjanya sebesar $14,81 \%$. Kegiatan program diversifikasi pangan yang telah dilaksanakan adalah pengembangan pekarangan dan peningkatan KAP. Kegiatan pengembangan pekarangan berupa lomba menu makanan dari hasil panen lokal daerah. Sedangkan kegiatan peningkatan KAP adalah penyuluhan tentang makanan yang beragam, bergizi dan berimbang, pemberian makanan tambahan untuk anak sekolah dan pemberian makanan pendamping ASI (MP-ASI).

Karakteristik selanjutnya adalah berdasarkan potensi lembaga dalam program pemanfaatan pekarangan. Program pemanfaatan pekarangan terdiri dari beberapa kegiatan, yaitu (1) Penyuluhan tentang paket teknologi pekarangan baik budidaya maupun pengolahan; (2) Percontohan desa intensif pekarangan; (3) Pendampingan dalam rangka pemberdayaan bagi kelompok wanita dalam pengembangan pekarangan; (4) Penguatan modal bagi kelompok wanita dalam pengembangan pekarangan; (5) Penyuluhan pangan beragam dan bergizi seimbang; (6) Lomba menu makanan dari hasil pekarangan; (7) Pengembangan depot desa dengan menu makanan berbasiskan sumberdaya pedesaan; dan (8) Penyusunan paket teknologi pekarangan.

Kelembagaan lokal mempunyai potensi
yang besar dalam membantu mengembangkan kegiatan pemanfaatan pekarangan, hal ini ditunjukkan oleh adanya kelembagaan lokal yang mempunyai kegiatan bersama dan pernah ada kegiatan pemanfaatan pekarangan yaitu sebesar $55,56 \%$ serta kelembagaan lokal yang mempunyai kegiatan bersama dan ada lebih dari tiga kali mempunyai kegiatan pemanfaatan pekarangan sebesar 29,63\%. Kegiatan pemanfaatan pekarangan yang pernah dilakukan oleh kelembagaan lokal adalah penguatan modal berupa simpan pinjam bagi kelompok wanita, penyuluhan pangan yang beragam, bergizi dan berimbang dan lomba menu makanan dari hasil pekarangan setiap tahunnya dalam rangka merayakan HUT RI dan penyuluhan tentang pekarangan baik budidaya maupun pengolahan (budidaya tanaman rosella dan 
cara pengolahannya). Kegiatan kelembagaan lokal yang rutin dilaksanakan adalah arisan, posyandu (untuk PKK), pengajian, tahlilan dan yasinan (untuk kelompok pengajian).

Karakteristik berikutnya adalah berdasarkan potensi lembaga dalam program pengembangan pangan lokal. Diketahui bahwa terdapat $29,63 \%$ kelembagaan lokal yang mempunyai kegiatan bersama tetapi tidak ada kegiatan pengembangan pangan lokal. Kegiatan bersama yang rutin dilaksanakan adalah arisan untuk anggota kelembagaan lokal, dan kegiatan-kegiatan lainnya yang sifatnya spesifik untuk masingmasing kelembagaan lokal, seperti posyandu untuk PKK, pengajian, tahlilan dan yasinan untuk kelompok pengajian baik pria maupun wanita. Terdapat $40,74 \%$ kelembagaan lokal yang mempunyai kegiatan dan pernah ada kegiatan pengembangan pangan local. Kegiatan pengembangan pangan lokal yang pernah dilaksanakan adalah pemberdayaan masyarakat dalam pengolahan bahan pangan lokal dan sosialisasi serta pelatihan produksi.

Karakteristik berikutnya adalah berdasarkan potensi lembaga dalam program pengembangan makanan tradisional. Kelembagaan lokal yang mempunyai kegiatan tetapi tidak ada kegiatan pengembangan makanan tradisional sebesar $29,63 \%$, kelembagaan lokal yang mempunyai kegiatan bersama dan pernah ada kegiatan pengembangan makanan tradisional sebesar $25,93 \%$ serta ada $44,44 \%$ kelembagaan lokal yang mempunyai kegiatan bersama dan mempunyai lebih dari tiga kali kegiatan pengembangan makanan tradisional. Kegiatan dalam pengembangan makanan tradisional yang pernah dilaksanakan oleh kelembagaan lokal adalah promosi pengembangan makanan tradisional yaitu dengan memberikan konsumsi berupa olahan makanan-makanan tradisional pada saat kegiatan, peningkatan peran organisasi masyarakat misalnya PKK dan penyelenggaraan lomba makanan tradisional. Dari sini dapat dilihat bahwa pengembangan makanan tradisonal sangat didukung oleh lembaga lokal seperti PKK, kelompok pengajian dan KWT.
Dalam menggerakkan kelembagaan local, kelembagaan yang mampu menggerakkan masyarakat masih lemah adalah $11,1 \%$; dan $29,6 \%$ kelembagaan lokal yang benar-benar mampu (kuat) menggerakkan masyarakat. Dengan kemampuannya menggerakkan masyarakat ini akan sangat baik jika kelembagaankelembagaan lokal tersebut diikutsertakan dalam program percepatan diversifikasi pangan agar program-program diversifikasi pangan lebih mudah disosialisasikan dan cepat diaplikasikan di masyarakat.

Selanjutnya adalah karakteristik kelembagaan lokal berdasarkan ada tidaknya pembinaan dari dinas-dinas terkait baik tingkat sebagian besar yaitu 29,63\% kelembagaan lokal pernah mendapat pembinaan dari dinas terkait baik dari tingkat Kabupaten maupun Propinsi. Walaupun ada sebagian kecil kelembagaan lokal lainnya yang pernah mendapatkan pembinaan dalam bentuk pelatihan untuk satu jenis program pengembangan diversifikasi pangan dan dua jenis program pengembangan diversifikasi pangan. Hal ini menunjukkan adanya dukungan dari dinas-dinas terkait baik ditingkat Kabupaten maupun Propinsi pada program percepatan Diversifikasi Pangan.

Karakteristik kelembagaan lokal berikutnya adalah berdasarkan sumber informasi yang terkait dengan program percepatan diversifikasi pangan terdapat $44,44 \%$ mengaku mendapatkan informasi dari PPL; dari tetangga dan media elektronik masing-masing $44,44 \%$ dan $11,15 \%$. Hasil penelitian menunjukkan bahwa banyak kelembagaan lokal mendapat informasi tentang diversifikasi pangan dari PPL dan tetangga, hal ini dapat menjadi salah satu faktor pendorong pengenalan program kepada masyarakat peranan dinas-dinas terkait sangat dibutuhkan agar program ini dapat terwujud.

\section{c. Karakteristik terhadap komponen kegiatan pengembangan pekarangan}

Dari hasil penelitian diketahui bahwa respon kelembagaan lokal terhadap kegiatan 
pengembangan pekarangan sangat baik, artinya mereka sangat mendukung kegiatankegiatan yang berhubungan dengan pengembangan pekarangan. Kegiatankegiatan yang termasuk dalam komponen pengembangan pekarangan adalah jumat bersih dengan menanam tanaman secara serentak baik di desa maupun di dusun, penyuluhan tentang paket teknologi pekarangan baik budidaya maupun pengolahan, pendampingan dalam rangka pemberdayaan bagi kelompok wanita dalam pengembangan pekarangan, penyuluhan pangan beragam dan bergizi seimbang, lomba menu makanan dari hasil pekarangan, dan penyusunan paket teknologi pekarangan (KRPL). Selain itu kelembagaan lokal juga menganggap program tersebut sangat bermanfaat bagi anggota pada khususnya dan bagi masyarakat pada umumnya. Kelembagaan lokal juga menganggap kegiatan-kegiatan yang berhubungan dengan pengembangan pekarangan mudah untuk diaplikasikan baik untuk anggota kelembagaan lokal sendiri maupun untuk disebarluaskan pada masyarakat lainnya diluar kelembagaan. Dan yang paling penting adalah mereka sanggup untuk mendukung pelaksanaan kegiatan pemanfaatan pekarangan.

\section{d. Karakteristik kelembagaan lokal terhadap komponen kegiatan pengembangan pangan lokal}

Dari hasil penelitian diketahui bahwa respon kelembagaan lokal terhadap kegiatan pengembangan pangan lokal netral saja. Begitu juga pada point manfaat dari pengembangan pangan lokal dan kemudahan dalam mengaplikasikan program pangan lokal. Namun demikian kelembagaan lokal yang ada menyatakan kesanggupannya untuk ikut melaksanakan kegiatan pengembangan pangan lokal, tetapi harus didukung oleh dinas-dinas terkait baik yang berada di tingkat Kabupaten. Dinas-dinas terkait harus lebih meningkatkan dukungannya pada kegiatan-kegiatan pengembangan pangan lokal. Kegiatan-kegiatan yang termasuk dalam komponen pengembangan pangan lokal adalah promosi pengembangan pangan lokal; sosialisasi dan pelatihan produksi dan pemasaran; pembinaan/pendampingan, pemantauan dan evaluasi; pemberdayaan masyarakat dalam pengolahan bahan pangan lokal; pemasyarakatan teknologi pengolahan pangan yang berbasis spesifik daerah; penemuan paket teknologi pengolahan pangan non beras; peningkatan peran masyarakat, meningkatkan kemitraan antara industri rumah tangga (UMKM) dengan industri menengah; pembinaan UMKM pengolahan bahan pangan nabati dan hewani dari pangan asli; identifikasi potensi pangan lokal sesuai kondisi daerah; dan pemetaan sumber daya lokal nabati dan hewani pada tingkat wilayah.

\section{e. Karakteristik kelembagaan lokal terhadap komponen kegiatan pengembangan makanan tradisional}

Pada kegiatan pengembangan makanan tradisional kelembagaan-kelembagaan lokal bersikap netral, baik dalam merespon program pengembangan makanan tradisional, manfaat kegiatan pengembangan makanan tradisional maupun kemudahan dalam mengaplikasikan kegiatan tersebut. Namun mereka menyatakan siap membantu melaksanakan kegiatan pengembangan makanan tradisional. Kegiatan-kegiatan yang termasuk pada komponen pengembangan makanan tradisional adalah promosi pengembangan makanan tradisional; sosialisasi dan pelatihan, pembinaan, pendampingan, pemantauan dan evaluasi; promosi makanan tradisional peningkatan peran organisasi masyarakat; pemberdayaan kelompok wanita di perkotaan dan perdesaan; mendorong industry pangan tradisional untuk mengembangkan usahanya; penyelenggaraan festival dan lomba makanan tradisional,; pemberdayaan masyarakat dalam pengembangan produk olahan makanan tradisional untuk meningkatkan daya tarik, cita rasa dan citra makanan tradisional; penelitian dan pengembangan menu serta teknologi olahan makanan tradisional yang 
memperhatikan mutu gizi dan keamanan pangan; pemasyarakatan teknologi pengolahan, pengemasan dan penyajian dalam penerapan teknologi maju, spesifik wilayah serta memperhatikan mutu gizi dan keamanan pangan; identifikasi makanan tradisional sesuai potensi daerah; dan pemetaan profil makanan tradisional unggulan tingkat wilayah. Seperti halnya pada pengembangan pangan lokal, pada pengembangan makanan tradisionalpun pemerintah khususnya dinas-dinas terkait juga harus meningkatkan dukungannya terhadap pengembangan makanan tradisional

\subsection{Klasifikasi Kelembagaan Lokal Berdasarkan Potensinya Dalam Mendukung Percepatan Program Diversifikasi Pangan}

Pengklasifikasian kelembagaan lokal pada penelitian ini dilakukan dengan menggunakan bantuan SPSS (Statistical Program for Social Sciencie). Hasil analisa ditunjukkan pada rekap pada tabel 9.

Tabel 1. Hasil Pengklasifikasian/Pengklasteran

\begin{tabular}{c|c|l}
\hline $\begin{array}{c}\text { Klasifikasi } \\
\text { / Klaster }\end{array}$ & $\begin{array}{c}\text { Jumlah } \\
\text { Anggota }\end{array}$ & \multicolumn{1}{c}{ Nama dan Nomor Kelembagan Lokal } \\
\hline & 10 & $\begin{array}{l}\text { PKK Desa Gerbo (10), BPD Gerbo (11), BPD Pucang sari (3), } \\
\text { PKK Pucang Sari (4), Kelompok Tani Pucang sari (5), PKK Desa } \\
\text { Suwayuwo (16), Kelompok Tani Gerbo (2), Jam'iah Tahlil Pria } \\
\text { Pucang sari (8), Kelompok Tani Suwayuwo (18) dan PKK Desa } \\
\text { Pandaan (1), KWT Gerbo (20), KWT Pucang sari (25), Muslimat } \\
\text { NU Pandaan (22),Muslimat NU Suwayuwo(24) }\end{array}$ \\
\hline II & 9 & $\begin{array}{l}\text { Muslimat Gerbo (6), Muslimatan Pucang sari (13), Kelompok } \\
\text { Tani Pandaan (9), Kelompok Pengajian Pria Pucang sari (14), } \\
\text { Karang Taruna Pucang sari (7), BPD Pandaan(12), BPD } \\
\text { Suwayuwo (17), Karang Taruna Suwayuwo (19) dan Karang } \\
\text { Taruna Pandaan (15). KWT Suwayuwo (21), KWT Pandaan } \\
\text { (23),Jamaah tahlil pria Gerbo(26), Jamaah Tahlil Pria Pandaan } \\
\text { (27) }\end{array}$ \\
\hline
\end{tabular}

Sumber : Data Primer, 2013 (diolah).

Dari tabel 1 diketahui bahwa secara umum kelembagaan lokal yang tergabung pada klasifikasi I adalah kelembagaankelembagaan lokal yang lebih aktif dibandingkan dengan kelembagaankelembagaan lokal yang tergabung pada klasifikasi II. Pengklasifikasian/pengklasteran tidak bermanfaat apabila tidak diketahui profil dari setiap klaster. Untuk menginterpretasikan klaster dan membuat profil mereka, digunakan rata-rata setiap klaster pada setiap variabel (yang dinamakan centroid). Dengan centroid memungkinkan untuk memberi label pada setiap klaster.
Berdasarkan variabel-variabel tersebut dapat diinterpretasikan bahwa profil klasifikasi/klaster I (satu) adalah kelembagaan lokal yang potensial untuk mendukung percepatan program diversifikasi pangan. Dengan diketahuinya profil masingmasing klasifikasi/klaster kelembagaan lokal ini, maka dapat dijadikan acuan bagi pemerintah untuk memilih kelembagaankelembagaan lokal mana saja yang dapat membantu percepatan program diversifikasi pangan di Kabupaten Pasuruan. 


\section{KESIMPULAN DAN SARAN}

\section{Kesimpulan}

Berdasarkan hasil penelitian dan pembahasan maka dapat disimpulkan sebagai berikut :

1. Didaerah penelitian terdapat 27 kelembagaan lokal yang mempunyai potensi untuk mendukung percepatan program diversifikasi pangan. Kelembagaan tersebut terdiri dari 4 kelembagaan PKK, 4 kelembagaan BPD, 4 kelembagaan kelompok tani, 4 kelembagaan pengajian, 3 kelembagaan karang taruna dan 4 Koperasi wanita Tani (KWT)

2. Peran kelembagaan lokal berdasarkan potensinya dalam mendukung percepatan program diversifikasi pangan di Pasuruan menunjukkan bahwa kelembagaan yang berpotensi mendukung program Deversivikasi Pangan adalah pada klasifikasi I yaitu PKK Desa Gerbo, BPD Gerbo, BPD Pucang sari, PKK Pucang Sari, Kelompok Tani Pucang sari, PKK Desa Suwayuwo, Kelompok Tani Gerbo, Jam'iah Tahlil Pria Pucang sari, Kelompok Tani Suwayuwo, PKK Desa Pandaan, KWT Gerbo, KWT Pucang sari, Muslimat NU Pandaan,Muslimat NU Suwayuwo

\section{Saran}

Berdasarkan hasil penelitian yang diperoleh maka dapat disarankan :

1. Perlu menumbuhkan, mengembangkan dan memberdayakan usaha-usaha ekonomi mandiri yang bertujuan untuk meningkatkan pendapatan masyarakat sehingga masyarakat dapat mengkonsumsi makanan yang bergizi dan beragam. Usaha-usaha ekonomi mandiri hendaknya yang berhubungan dengan usaha perbaikan gizi masyarakat, misalnya usahatani terpadu;

2. Perlu adanya koordinasi antar instansi terkait sehingga program-program yang dilaksanakan dapat saling mendukung dan mempunyai satu tujuan. Program-program tersebut hendaknya difokuskan untuk kelembagaan lokal yang potensial, misalnya kelembagaan Pemberdayaan Kesejahteraan Keluarga (PKK), sehingga program-program tersebut dapat lebih efektif.

\section{DAFTAR PUSTAKA}

Ariani, 2008. Keberhasilan Diversifikasi Pangan Tanggung Jawab Bersama. Balai Pengkajian Teknologi Pertanian Banten.

Arifin B., 2005. Ekonomi Kelembagaan Pangan. LP3ES, Jakarta.

Dwiastuti, 2008. Skenario Kebijakan Diversifikasi Konsumsi Pangan Berbasiskan Perilaku Rumah Tangga dan Kelembagaan Lokal. Laporan Hasil Penelitian. Lembaga Penelitian dan pengabdian Masyarakat, Universitas Brawijaya, Malang.

Hermanto R., 2007. Rancangan Kelembagaan Tani Dalam Implementasi Prima Tani Di Sumatera Selatan. Jurnal Analisis Kebijakan Pertanian Volume 5 Nomor 2, Juni 2007. Pusat Analisis Sosial Ekonomi dan Kebijakan Pertanian.

Mubyarto, 1988. Pembangunan Pedesaan di Indonesia. Liberty, Yogyakarta.

Nurcahayati Eneng, 2008. Perlu Percepatan Diversifikasi Pangan. Radar banten. http://www.radarbanten.com/mod.p hp?mod=publisher\&op=viewarticle \&artid=35835. Diunduh 11 Oktober 2012. 
Pangarsa, dkk., 2006. Pengkajian Penguatan Kelembagaan Petani dan Agribisnis di Lokasi LItkaji Yang Sedang Berjalan. Laporan Akhir Pengkajian. Balai Pengkajian Teknologi Pertanian (BPTP). Jawa Timur.

Rahayu Ani Sri, 2006. Peran Institusi Lokal Dalam Pembangunan Desa. Tesis. Universitas Brawijaya, Malang.

Rozi Fachrur, 2006. Hambatan Diversifikasi Pangan Masyarakat Jawa Timur. http://www.balitbangjatim.com/b ul_d2.asp?id_subBab=55. Diunduh 11 Oktober 2012.

Wiriatmadja, Soekandar, 1987. Pokokpokok Sosiologi Pedesaan. CV. Yasaguna, Jakarta. 